\title{
Amphiphilic Carborane-Containing Diblock Copolymers
}

Yoan C. Simon, Christian Ohm, Melanie J. Zimny and E. Bryan Coughlin*

Department of Polymer Science and Engineering, University of Massachusetts, Amherst, MA 01003

Email: $\underline{\text { Coughlin@ mail.pse.umass.edu }}$

\section{Supporting Information}




\section{Experimental Section}

Materials. All organic reactants and reagents were purchased from Aldrich Chemical Co and used as received unless specified otherwise. Anhydrous benzene and diethyl ether were dried over sodium with benzophenone as an indicator. Dichloromethane (DCM) was obtained through Fisher, distilled over calcium hydride and degassed with freezepump-thaw cycles. O-carborane was supplied by KatChem. ${ }^{1}$ Grubbs' third generation catalyst was synthesized according to the literature procedure and stored under nitrogen atmosphere. $^{2}$

Instrumentation. Gel permeation chromatography (GPC) measurements for the homopolymers 4 were performed in tetrahydrofuran (THF) at $1.0 \mathrm{~mL} / \mathrm{min}$ using a Knauer K-501 Pump with a K-2301 refractive index detector and a K-2600 UV detector, and a column bank consisting of two Polymer Labs PLGel Mixed D columns at $40^{\circ} \mathrm{C}$. All other measurements were performed using a similar system with a column banks consisiting of three Polymer Labs PLGel Mixed D columns at $40^{\circ} \mathrm{C}$. Molecular weights are reported relative to polystyrene standards.

${ }^{1} \mathrm{H}$ NMR, ${ }^{11} \mathrm{~B}$ NMR and ${ }^{13} \mathrm{C}$ NMR were recorded at $300 \mathrm{MHz}, 128 \mathrm{MHz}$ and 100 $\mathrm{MHz}$ respectively on a Bruker NMR spectrometer at room temperature in deuterated chloroform. The individual NMR spectral assignments do not list the carborane B-H resonances. Due to the quadrupolar nature of boron, the resonances for the $10 \mathrm{~B}-\mathrm{H}$ are observed as broad multiplets $(\delta(\mathrm{ppm})=3.20-1.01)$. The integration of these multiplets accounts for $10 \mathrm{H}$. Melting points were measured with a melting point apparatus Electrochemical Mel-Temp in a capillary tube.

Dynamic Light Scattering (DLS) was performed in $18 \mathrm{~m} \Omega$ water. The sample was prepared as followed; $30 \mathrm{mg}$ of deprotected polymer were first dissolved in dimethyl sulfoxide DMSO $(30 \mathrm{~mL})$. To this solution, $30 \mathrm{~mL}$ of $18 \mathrm{~m} \Omega$ water were added using a syringe pump at a rate of $15 \mathrm{~mL} / \mathrm{h}$. The solution was then transferred into a dialysis bag and dialyzed against $2 \mathrm{~L}$ of $18 \mathrm{~m} \Omega$ water for 2 days, renewing the water three times along the process. All experiments were performed at room temperature using an ALV unit equipped with an ALV/SP-125 precision goniometer (ALV-Laser Vertriebsgessellschaft m.b.h.), an Innova 70 argon laser $\left(\lambda_{0}=514.5 \mathrm{~nm}\right.$, max. power $3 \mathrm{~W}$, Coherent Inc.) operated at $300 \mathrm{~mW}$, and a photomultiplier detector (Thorn EMI Electron Tubes). Signal 
from the detector was processed by an ALV 5000 Multiple Tau Digital Correlator board and associated software. The solutions were prefiltered through PVDF filters of $0.25-\mathrm{mm}$ pore size. The experiment was performed using a polymer $(\mathrm{PDI}=1.10, \mathrm{Mn}=30.500$ $\mathrm{g} / \mathrm{mol}$ with complete deprotection as monitored by ${ }^{1} \mathrm{H} \mathrm{NMR}$, molar ratio (SONIC/BONIA) $=2 / 1)$

\section{Preparation of the 1-(tert-butyl-dimethylsilanyl)-1,2-dicarba-closo-}

dodecaborane(12) 1. Compound 1 was prepared using a slight modification of a Hawthorne procedure. ${ }^{3}$ In a round-bottom $500 \mathrm{~mL}$ Schlenk flask capped with a rubber septum and equipped with a magnetic stir bar. Under a nitrogen atmosphere, sublimed ocarborane (15 g, $104 \mathrm{mmol}, 1 \mathrm{eq})$ in a 2:1 mixture of benzene/ether $(40 \mathrm{~mL} / 20 \mathrm{~mL})$ was deprotonated using n-butyl-lithium (78 mL, nBuLi $1.6 \mathrm{M}, 125 \mathrm{mmol}, 1.2 \mathrm{eq})$ at $0^{\circ} \mathrm{C}$ dropwise. After $45 \mathrm{~min}$, t-butyldimethylsilyl (TBDMS) chloride (TBDMS-Cl, $20.4 \mathrm{~g}$, $135 \mathrm{mmol}, 1.3 \mathrm{eq})$ in $30 \mathrm{~mL}$ of a benzene/ether $(2: 1 \mathrm{~V}: \mathrm{V})$ solution was added. After the addition of the silyl compound, the stopcock was closed and the septum removed. A rubber septum-capped condenser was fitted on top of the reaction flask with a nitrogen overpressure. The stopcock was then opened and the solution was brought to reflux. After refluxing overnight, the solution was quenched with a few drops of methanol to prevent exothermic reaction upon addition of $40 \mathrm{~mL}$ of water. The layers were separated in a separatory funnel and the aqueous solution was extracted with additional $\mathrm{Et}_{2} \mathrm{O}(2 \times 40$ $\mathrm{mL}$ ). The combined extracts were dried over $\mathrm{MgSO}_{4}$ and concentrated in vacuo to give a slightly yellowish solid that was then distilled $\left(85^{\circ} \mathrm{C}, 20 \mathrm{mTorrs}\right)$ to yield $24.7 \mathrm{~g}$ of a white powder, silyl-o-carborane 1 ( $92 \%$ yield). Also, there was no trace of remaining ocarborane. To verify the absence of any starting material in the final product, a careful sweep of temperatures, from $20^{\circ} \mathrm{C}$ up to $85^{\circ} \mathrm{C}$, at constant pressure $(10 \mathrm{mTorrs})$ was performed with no apparent condensation of any solid prior to the final temperature. Conversely, keeping a constant temperature $\left(85^{\circ} \mathrm{C}\right)$ and carefully decreasing the pressure in the system, from 1 atm down to 10 mTorrs, no remaining o-carborane condensation was noted. High Resolution MS (EI+): m/z calcd 258.2758, found 258.4915; ${ }^{1} \mathrm{H}$ NMR $\left(\mathrm{CDCl}_{3}\right): \delta(\mathrm{ppm})=3.46(\mathrm{~s}, 1 \mathrm{H}, \mathrm{CH}), 1.03\left(\mathrm{~s}, 9 \mathrm{H}, \mathrm{CCH}_{3}\right), 0.26\left(\mathrm{~s}, 6 \mathrm{H}, \mathrm{SiCH}_{3}\right) ;{ }^{13} \mathrm{C} \mathrm{NMR}$ $\left(\mathrm{CDCl}_{3}\right): \delta(\mathrm{ppm})=66.02,60.25,26.98,19.32,-4.56 ;{ }^{11} \mathrm{~B}\left\{{ }^{1} \mathrm{H}\right\} \mathrm{NMR}\left(\mathrm{CDCl}_{3}\right): \delta(\mathrm{ppm})$ $=0.28(1 \mathrm{~B}),-1.80(1 \mathrm{~B}),-7.03(2 \mathrm{~B}),-10.75(2 \mathrm{~B}),-13.28(2 \mathrm{~B}) ; \mathrm{mp}=61^{\circ} \mathrm{C}$. 
Preparation of the [2-(tert-butyl-dimethyl-silanyl)-1,2-dicarba-closododecaboran(12)-1-yl]-propan-1-ol 2. Compound 2 was prepared using a slight modification of a Hawthorne procedure in a setup comparable to the one used for $\mathbf{1}^{3}$ Under a nitrogen atmosphere, compound 1 (15 g, $58 \mathrm{mmol}, 1 \mathrm{eq})$ in benzene/ether (2:1 $\mathrm{V}: \mathrm{V})$ was deprotonated using dropwise addition of $\mathrm{nBuLi}(43.5 \mathrm{~mL}$ of a $1.6 \mathrm{M}$ solution, $69.6 \mathrm{mmol}, 1.2 \mathrm{eq})$ at $0^{\circ} \mathrm{C}$. Trimethylene oxide (4.9 mL, $\left.75.4 \mathrm{mmol}, 1.3 \mathrm{eq}\right)$ was added after $45 \mathrm{~min}$ and the solution turned light yellow. The solution was refluxed overnight and turned orange. The reaction was quenched with a few drops of methanol and $40 \mathrm{~mL}$ of water. The layers were separated in a separatory funnel and the aqueous solution was extracted with additional $\mathrm{Et}_{2} \mathrm{O}(2 \times 40 \mathrm{~mL})$. The combined extracts were dried over $\mathrm{MgSO}_{4}$ and concentrated in vacuo to give a sticky solid. The paste was then recrystallized from boiling hexanes followed by cooling at $-4^{\circ} \mathrm{C}$. The thin fibrous white crystals were then filtered over sintered glass to obtain $15.6 \mathrm{~g}$ of carboranylpropanol 2 (85\% yield). High Resolution MS (EI+): m/z calcd 315.3160, found 315.3155; ${ }^{1} \mathrm{H}$ NMR $\left(\mathrm{CDCl}_{3}\right): \delta(\mathrm{ppm})=3.69\left(\mathrm{q}, 2 \mathrm{H}, \mathrm{CH}_{2} \mathrm{OH}\right), 2.34\left(\mathrm{qu}, 2 \mathrm{H}, \mathrm{CH}_{2} \mathrm{CH}_{2} \mathrm{OH}\right), 1.78\left(\mathrm{t}, 2 \mathrm{H}, \mathrm{CH}_{2^{-}}\right.$ Cage), $\left.1.06\left(\mathrm{~s}, 9 \mathrm{H}, \mathrm{CCH}_{3}\right), 0.31\left(\mathrm{~s}, 6 \mathrm{H}, \mathrm{SiCH}_{3}\right) ;\right) ;{ }^{13} \mathrm{C} \mathrm{NMR}\left(\mathrm{CDCl}_{3}\right): \delta(\mathrm{ppm})=81.28$, 76.47, 61.55, 35.51, 34.68, 27.80, 20.35, -2.48; ${ }^{11} \mathrm{~B}\left\{{ }^{1} \mathrm{H}\right\} \mathrm{NMR}\left(\mathrm{CDCl}_{3}\right): \delta(\mathrm{ppm})=0.21$ (1B), $-3.95(1 \mathrm{~B}),-7.33(2 \mathrm{~B}),-10.31(6 \mathrm{~B}) ; \mathrm{mp}=83^{\circ} \mathrm{C}$.

Preparation of (1R,2R,6S,7S)-4-\{3-[2-(tert-Butyl-dimethylsilanyl)-1,2-dicarbacloso-dodecaboran(12)-1-yl]propyl\}-10-oxa-4-aza-tricyclo[5.2.1.0 $\left.{ }^{2,6}\right]$ dec-8-ene-3,5dione referred to as Silyl-protected OxoNorbornene Imide Carborane (SONIC) 3. In a dry $500 \mathrm{~mL}$ flask, exo-7-oxonorbornene imide (7.6 g, $46 \mathrm{mmol}, 1 \mathrm{eq})$, [2-(tert-butyldimethyl-silanyl)-1,2-dicarba-closo-dodecaboran(12)-1-yl]-propan-1-ol 2 (16 g, 51 mmol, $1.1 \mathrm{eq})$ and triphenylphosphine (13.3 g, $51 \mathrm{mmol}, 1.1 \mathrm{eq})$ were dissolved upon stirring in $300 \mathrm{~mL}$ of freshly distilled dry tetrahydrofuran (THF). The flask was kept under nitrogen pressure and cooled down to $0^{\circ} \mathrm{C}$ with an ice bath. After 5 minutes, diisopropylazodicarboxylate (DIAD) $(3.2 \mathrm{~mL}, 16.26 \mathrm{mmol}, 1.1 \mathrm{eq})$ was added and the solution turned yellow. The reaction was allowed to react overnight (16 h) affording a deep-yellow solution. The crude mixture was then concentrated in vacuo to obtain a sticky yellow paste. The paste was then redissolved in minimum amount of THF and precipitated by dropwise addition into hexanes $(800 \mathrm{~mL})$. The precipitate was a white 
powder with a slight reddish tint. The powder was then redissolved and precipitated a second time. The precipitate was then recrystallized from boiling methanol followed by cooling at $-4^{\circ} \mathrm{C}$, affording $18.6 \mathrm{~g}$ of flat square white crystals (87\% yield). High Resolution MS (FAB-): m/z calcd 463.3505, found 463.3560; ${ }^{1} \mathrm{H}$ NMR $\left(\mathrm{CDCl}_{3}\right): \delta(\mathrm{ppm})$ $=6.52(\mathrm{~s}, 2 \mathrm{H}, \mathrm{CH}=\mathrm{CH}), 5.24$ (s, 2H, bridgeheads), $3.46\left(\mathrm{t}, 2 \mathrm{H}, \mathrm{NCH}_{2}\right), 2.85(\mathrm{~s}, 2 \mathrm{H}$, $\mathrm{NC}(\mathrm{O}) \mathrm{CH}$ ), $2.09\left(\mathrm{~m}, 2 \mathrm{H}, \mathrm{NCH}_{2} \mathrm{CH}_{2}\right), 1.82\left(\mathrm{~m}, 2 \mathrm{H}, \mathrm{NCH}_{2} \mathrm{CH}_{2} \mathrm{CH}_{2}\right), 1.06$ (s, 9H, $\left.\mathrm{CCH}_{3}\right)$ $0.32\left(\mathrm{~s}, 6 \mathrm{H}, \mathrm{SiCH}_{3}\right) ;{ }^{13} \mathrm{C} \mathrm{NMR}\left(\mathrm{CDCl}_{3}\right): \delta(\mathrm{ppm})=176.13,136.53,80.96,80.37,75.92$, $47.43,37.97,34.98,28.31,27.51,20.39,-2.60 ;{ }^{11} \mathrm{~B}\left\{{ }^{1} \mathrm{H}\right\} \mathrm{NMR}\left(\mathrm{CDCl}_{3}\right): \delta(\mathrm{ppm})=0.31$ (1B), -3.85 (1B), -7.49 (2B), $-10.25(6 \mathrm{~B}) ; \mathrm{mp}=136^{\circ} \mathrm{C}$.

Homopolymerization of SONIC 4. The procedure was the same for every homopolymerization. Here is a standard procedure for the reactions carried out in septum vials, under constant agitation and under nitrogen atmosphere. To a $1 \mathrm{~mL}$ of solution of the desired amount of Grubbs $3^{\text {rd }}$ generation catalyst, $200 \mathrm{mg}$ of monomer $(4.31 \mathrm{mmol})$ in $10 \mathrm{~mL}$ of dichloromethane were introduced rapidly and stirred for 6 minutes. After that time, the reaction was quenched with an excess of ethylvinylether and precipitated dropwise in cold methanol $(150 \mathrm{~mL})$ to afford a white powder. Table $\mathrm{S} 1$ shows the results obtained for different monomer to catalyst ratios. ${ }^{1} \mathrm{H} \mathrm{NMR}\left(\mathrm{CDCl}_{3}\right): \delta(\mathrm{ppm})=6.09$ (br s, $0.84 \mathrm{H}$, olefin trans), 5.82 (br s, $1.16 \mathrm{H}$, olefin cis), 5.02 (br t, 1.16, CHO, cis), 4.46 (br s, 0.84H, CHO, trans), 3.6-3.2 (m, 4H, N-CH $\mathrm{CH}_{2} \mathrm{CH}-\mathrm{C}(\mathrm{O})$ ), 3.0-1.3 (br, $14 \mathrm{H}, \mathrm{BH}, \underline{\mathrm{C}}_{2} \underline{\mathrm{C}}_{2}$ ), $1.08\left(\mathrm{~s}, 9 \mathrm{H}, \mathrm{CCH}_{3}\right), 0.34$ (s, $\left.6 \mathrm{H}, \mathrm{SiCH}_{3}\right) ;{ }^{13} \mathrm{C} \mathrm{NMR}\left(\mathrm{CDCl}_{3}\right): \delta(\mathrm{ppm})=175.31,131.10$, 80.96, 80.18, 76.24, 52.37, 38.07, 35.13, 28.46, 27.54, 20.40, -2.47.

Diblock copolymer synthesis 6. In a screw cap vial under nitrogen atmosphere and constant agitation, the desired amount of SONIC was dissolved in $5 \mathrm{~mL}$ of DCM and the catalyst was introduced as a $10 \mathrm{mM}$ solution in DCM. After $5 \mathrm{~min},\{2-[(1 \mathrm{R}, 2 \mathrm{R}, 6 \mathrm{~S}, 7 \mathrm{~S})$ 3,5-Dioxo-10-oxa-4-aza-tricyclo[5.2.1.02,6]dec-8-en-4-yl]-ethyl\}-carbamic acid tertbutyl ester referred to as Boc-protected OxoNorbornene Imide Amine (BONIA), dissolved in $5 \mathrm{~mL}$ of DCM, was introduced into the reaction media using a syringe. The reaction was quenched after $10 \mathrm{~min}$ by addition of excess ethyl vinylether. The solution was then precipitated into $50 \mathrm{~mL}$ of hexanes and filtered over sintered glass as a white solid. NMR spectrum showed below (Figure S2). 
Deprotection; Synthesis of an amphiphilic diblock copolymer 7: In a $35 \mathrm{~mL}$ round-bottom flask, the polymer $(150 \mathrm{mg})$ was dissolved in $4 \mathrm{~mL}$ of DCM and $15 \mathrm{~mL}$ of trifluoroacetic acid and allowed to react overnight. The polymer salt was then precipitated in diethyl ether and filtered over sintered glass. NMR spectrum showed below (Figure S2).

\section{Additional Data.}

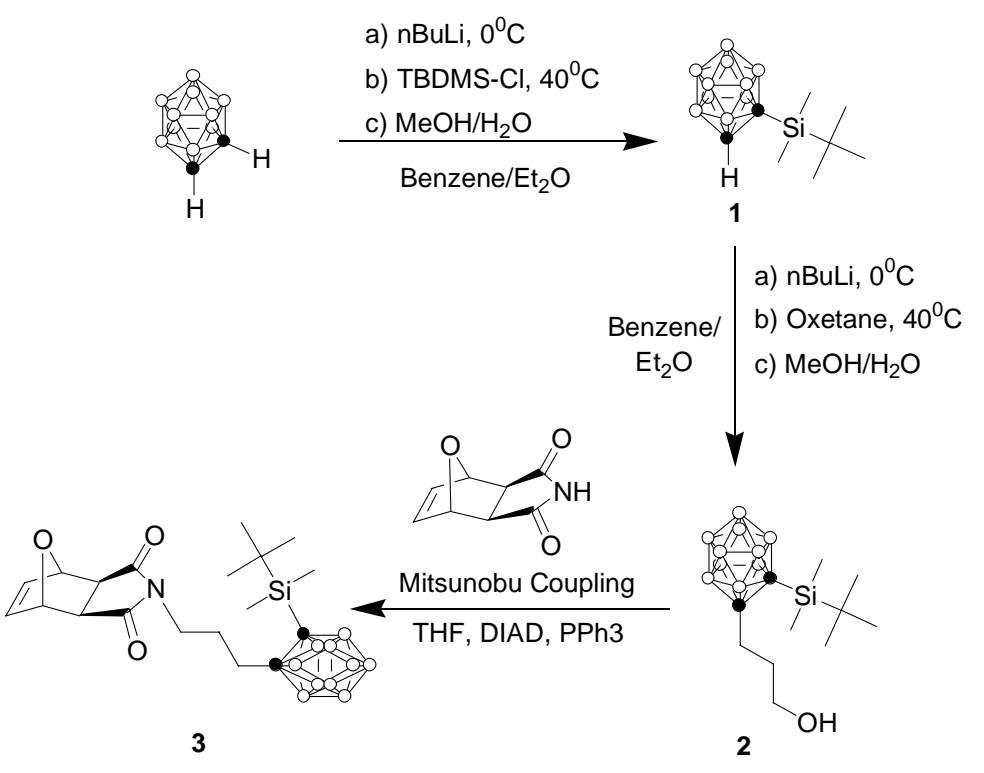

Figure S1: Synthesis of the SONIC monomer 3. TBDMS: terbutyldimethylsilyl. DIAD: diisopropylazodicarboxylate. 


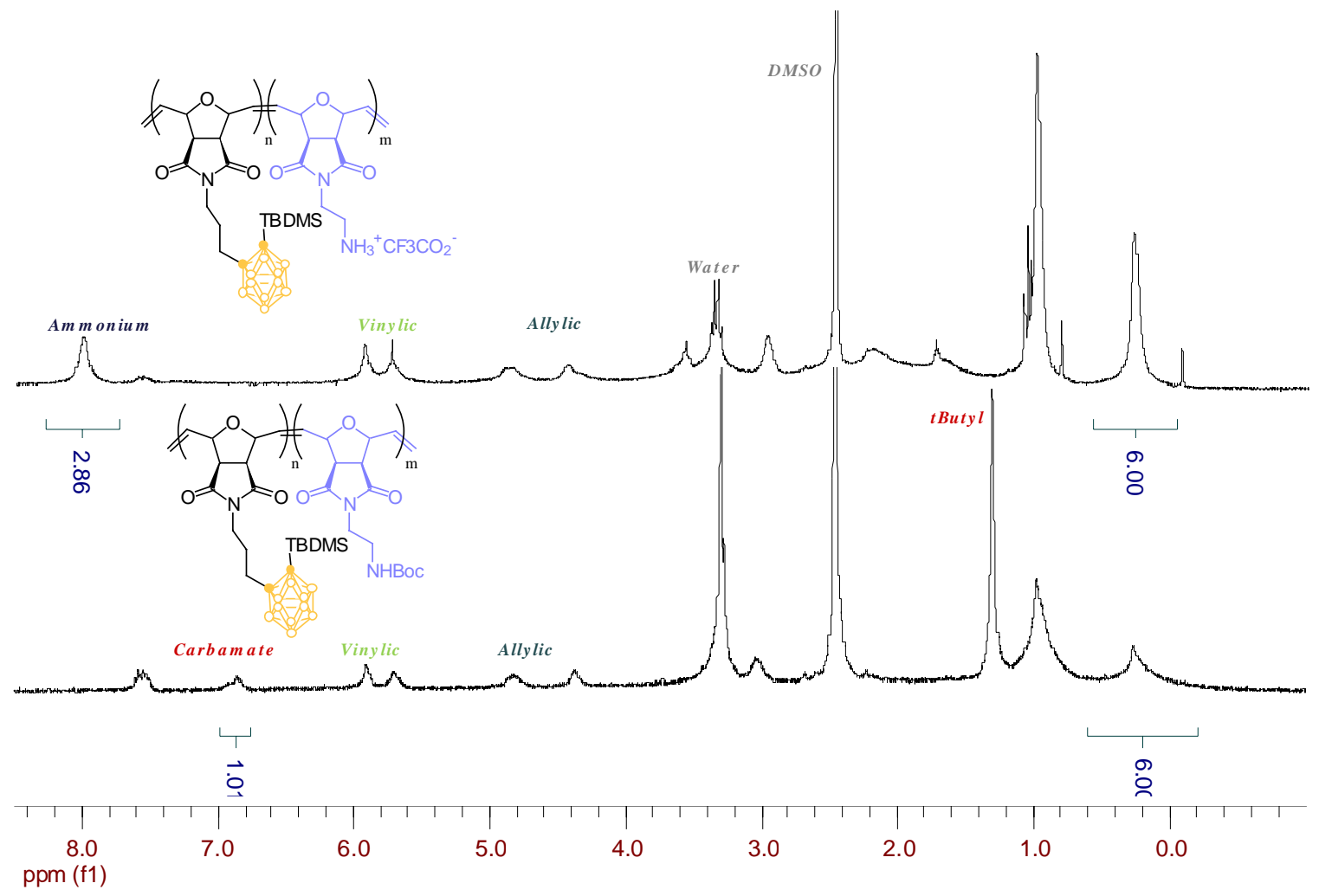

Figure S2: Illustration of the appearance of the ammonium peak at $8 \mathrm{ppm}$. 


\section{NMR Spectroscopy}

Scheme S1: Structure of SONIC and numbering of the different electronic environements.

a,1
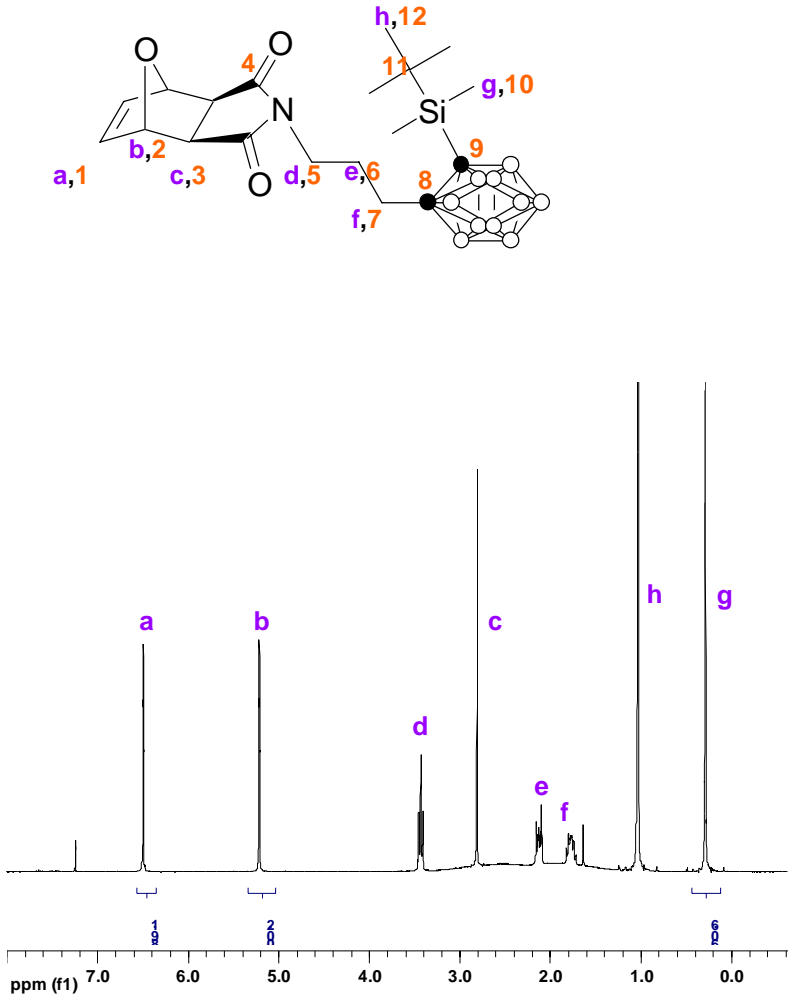

Figure S3. ${ }^{1} \mathrm{H}$ NMR of SONIC

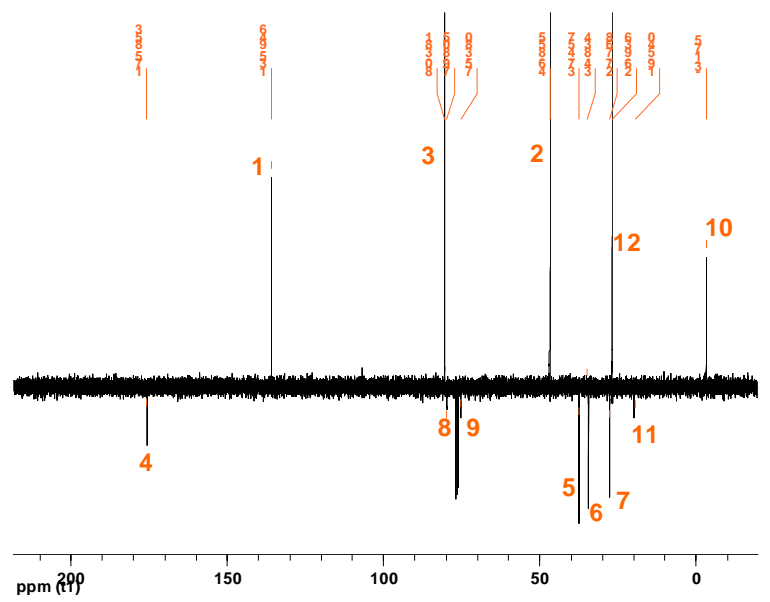

Figure S4: ${ }^{13} \mathrm{C}$ DEPT 135 NMR of SONIC 


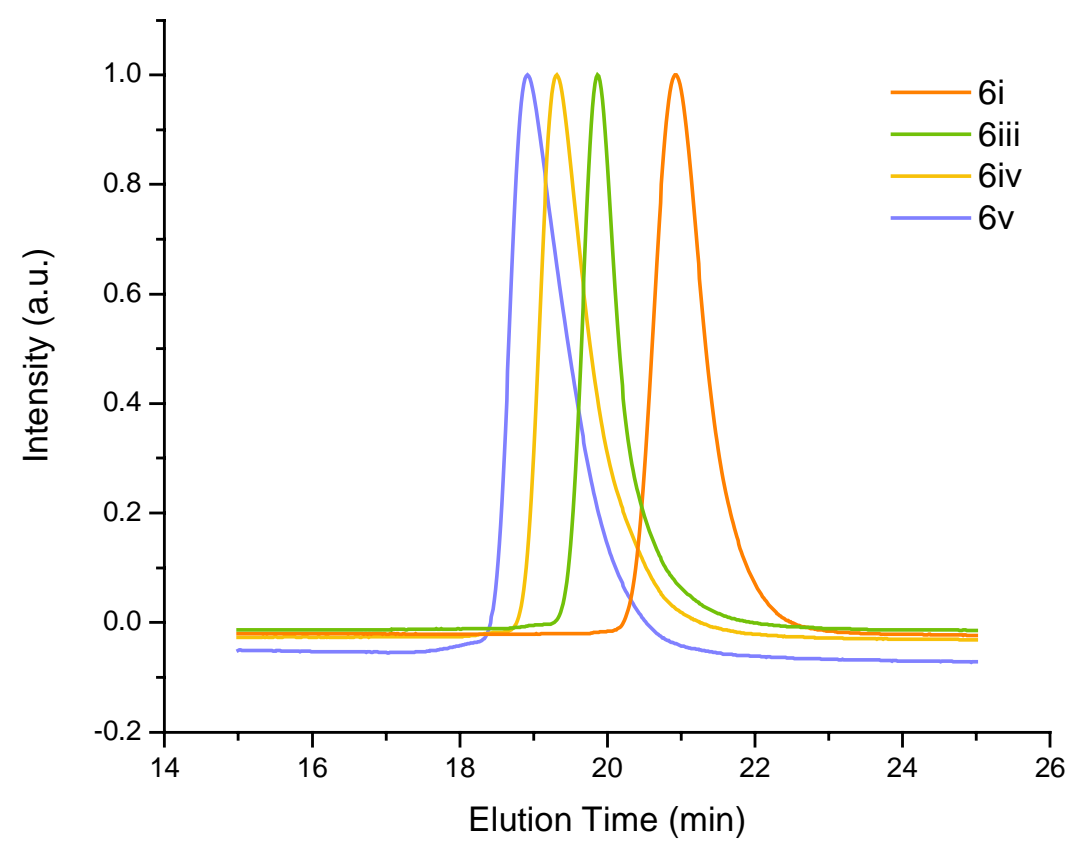

Figure S5: GPC chromatograms for the poly(SONIC- $b$-BONIA). For convenience, the traces were superimposed although they have no physical relation.

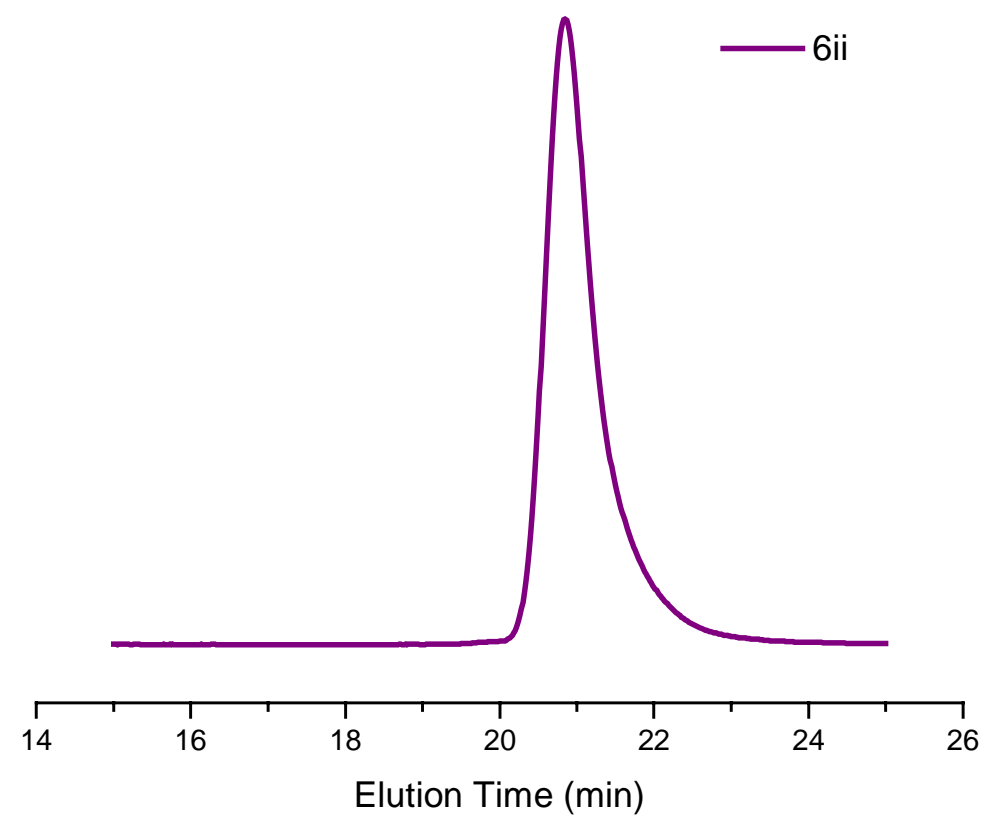

Figure S6: GPC chromatogram for Entry 6 ii. 
Figure S5 and S6 show the chromatograms for polymers 6i-6v. They illustrate the narrow polydispersities obtained by sequential addition of the monomers. The numerical data, namely polydispersity indices and molecular weights vs. polystyrene can be found in the main document (Table 1). Polymer 6ii was eluted months later than the other polymers and consequently the measurement took place using a different calibration curve. This difference explains the discrepancy in elution times between Entry 6ii (Figure S6) and Entry 6iii (Figure S5), despite their apparently comparable number average molecular weights.

Table S1: Homopolymerization of SONIC.

\begin{tabular}{llllll}
\hline & $\begin{array}{l}\text { Target } \\
\mathrm{DP}_{\mathrm{n}}\end{array}$ & $\begin{array}{l}\text { Target } \\
\mathrm{M}_{\mathrm{n}}{ }^{\mathrm{a}}\end{array}$ & $\mathrm{M}_{\mathrm{n}}^{\mathrm{a}, \mathrm{b}}$ & $\mathrm{PDI}^{\mathrm{a}}$ & Yield \\
\hline $4 \mathrm{i}$ & 54 & 25,000 & 22,000 & 1.07 & $83 \%$ \\
$4 \mathrm{ii}$ & 108 & 50,000 & 58,600 & 1.09 & $82 \%$ \\
$4 \mathrm{iii}$ & 162 & 75,000 & 79,100 & 1.05 & $87 \%$ \\
$4 \mathrm{iv}$ & 216 & 100,000 & 97,600 & 1.03 & $89 \%$ \\
\hline
\end{tabular}




\section{References}

(1) Zheng, L.; Farris, R. J.; Coughlin, E. B. J. Polym. Sci., Part A: Polym. Chem. 2001, 39, (17), 2920-2928.

(2) Love, J. A.; Morgan, J. P.; Trnka, T. M.; Grubbs, R. H. Angew. Chem., Int. Ed. Engl. 2002, 41, (21), 4035-4037.

(3) Gomez, F. A.; Johnson, S. E.; Hawthorne, M. F. J. Am. Chem. Soc. 1991, 113, (15), 5915-5917.

(4) Ilker, M. F.; Nuesslein, K.; Tew, G. N.; Coughlin, E. B. J. Am. Chem. Soc. 2004, 126, (48), 15870-15875. 